\title{
The Role of Stress-Protective Therapy in the Course of Chronic Cerebral Ischemia
}

\author{
DOI: $10.17691 / \mathrm{stm} 2015.7 .3 .14$
}

Received Mach 10, 2015

E.A. Antipenko, MD, PhD, Associate Professor, Department of Neurology, Psychiatry and Narcology,

Faculty of Doctors' Advanced Training';

M.Y. Maksimova, MD, DSc, Professor, Head of the $2^{\text {nd }}$ Neurological Unit2;

P.A. Soldatov, PhD, Associate Professor, Department of Surgery ${ }^{3}$

${ }^{1}$ Nizhny Novgorod State Medical Academy, 10/1 Minin and Pozharsky Square, Nizhny Novgorod, 603005,

Russian Federation;

${ }^{2}$ Neurology Research Center, 80 Volokolamskoe Shosse, Moscow, 125367, Russian Federation;

${ }^{3}$ Moscow State Academy of Veterinarian Medicine and Biotechnology named after K.I. Skryabin,

23 Academician Skryabin St., Moscow, 109472, Russian Federation

The aim of the investigation is to determine clinical and pathogenetic value of stress-protective therapy in the course of experimental chronic cerebral ischemia.

Materials and Methods. In the remote period of the experimental cerebral ischemia, simulated by occlusion of the middle cerebral artery, the survival and parameters of the behavioral activity of Wistar rats, the state of oxidative processes, indices of blood cell reactivity, and morphological brain tissue changes have been assessed.

Results. After simulation of chronic cerebral ischemia in the experimental animals impairment of homeostatic parameters regulation preserved for 60 days, manifesting themselves by alteration of behavioral and laboratory indices without marked movement disorders. Reduction of adaptive and compensatory process activity in animals in chronic cerebral ischemia resulted in the decrease of their survival in the observation period by $56 \%$. A combination of basic therapy with metabolic-type preparations provided $75 \%$ survival rate when antioxidants were used, and $100 \%$ survival when stress-limiting preparations were given. Inclusion of stress-limiting preparations in the therapeutic complex intensifies neuroprotective effect of the basic therapy and causes neurotrophic effect, maintaining cellular composition of the brain during chronic cerebral ischemia.

Conclusion. Neuroprotective effect of the stress-limiting preparation, given in the period of chronic cerebral ischemia, proves the hypothesis on the role of stress reaction in the pathogenesis of this disease. Findings of the experimental investigation confirmed the usefulness of including antistress preparations to the therapeutic complex in managing chronic cerebral ischemia.

Key words: chronic cerebral ischemia; stress-protective therapy.

Coordinated and balanced activity of stressogenic and stress-limiting systems provides stability of the body exposed to the damaging factors in the acute period of adaptation [1-5]. On the one hand, stress is a risk factor of cerebral ischemia development [6-9], on the other hand, insufficient blood supply of the brain, being a continually acting stress factor, causes adaptation failure and impairs homeostasis $[10,11]$. In the course of chronic cerebral ischemia a complex of compensatory and adaptive reactions is triggered to restore the damaged homeostasis in adaptation failure, caused by the strain and imbalance between the stress and stresslimiting systems.

Stress in animals is known to be characterized by the development of various humoro-hormonal and freeradical reactions. In some researches neuroprotective therapy is shown to elevate the resistance to stress [12-14]. Experimental studies have established, that synthetic analogs of neuropeptides and amino acids possess a marked stress-protective activity $[15,16]$. For example, neurochemical organization of the limbicohypothalamo-reticular structure in animals may be altered by additional introduction of delta sleep-inducing peptide [17], which suppresses excessive free radical formation and prevents neuron death in stress conditions [18].

A large number of investigations are devoted to post-stress changes, however, the role of stress in progressing chronic cerebral ischemia is remaining poorly studied as well as dynamics of post-stress reaction and morphofunctional alterations in the brain at different stages of chronic ischemia. The work presented here deals these questions.

The aim of the investigation is to determine clinical and pathogenetic value of stress-protective therapy in the course of experimental chronic cerebral ischemia.

Materials and Methods. The experimental part of the work was carried out at the Central Research Laboratory and the Department of Normal Physiology of Nizhny

For contacts: Antipenko Elena Albertovna, e-mail: antipenkoea@gmail.com 
Novgorod State Medical Academy. Investigations were performed on mature Wistar male rats weighing 250$300 \mathrm{~g}$ aged $3.5-4.0$ months.

The work was performed in accordance with ethical principles established by European Convention for the Protection of Vertebrate Animals used for Experimental and other Scientific Purposes (the Convention was passed in Strasburg of 18.03.1986, adopted in Strasburg of 15.06.2006) and approved by Ethics Committee of Nizhny Novgorod State Medical Academy. Animal keeping, surgical interventions and euthanasia were made according to the rules presented in "Guide for care and use of laboratory animals. ILAR publication, 1996, National Academy Press", and requirements of the Order of the Ministry of Health of the Russian Federation No.267 of 19.06.03 "About the approval of the rules of laboratory practice in the Russian Federation". Animals were kept in vivarium with a free access to food and water, in the condition of natural change of day and night.

Local cerebral ischemia was simulated by occluding the branch of the left middle cerebral artery and the vein going to it, with simultaneous ligation of the ipsilateral internal carotid artery. Infarction focus in the group of animals, receiving saline solution, occupied about $20 \%$ of the ipsilateral hemisphere. The head of the rat was fixed in the lateral position with the left side up. Once hair was removed and the operative site treated, the skin was cut along the zygomatic bone (about $2 \mathrm{~cm}$ ). The salivary gland together with the vascular plexus were separated from the adjacent tissues, replaced to the posterior superior square of the operative site and the zygomatic bone was removed. A sparing incision of the mandibular bone was made by a drill along the margin of temporal muscle tendon fixation. Then the lower margin of the temporal muscle was elevated by the hooks and the temporal fossa, the bottom of which is formed by the pterygoid muscle with the mandibular nerve going nearby, was exposed. The pterygoid muscle was moved apart by a retractor, the skull surface was cleared between the oval foramen and optic nerve opening. A hole about $2 \mathrm{~mm}$ in diameter was drilled under the low margin of the temporomandibular joint opening the region of the middle cerebral artery. Occlusion of the left branch of the middle cerebral artery was performed nearer to the place of its division into the frontal and parietal branches. Occlusion of the adjacent cerebral vein was made in the same way up to its intersection with the artery. Occlusion was achieved by electrocoagulation using electrosurgical high frequency device FOTEK E81 (FOTEK, Russia). Blood flow in the middle cerebral artery stopped after the occlusion, as can be viewed under the microscope. Immediately after coagulation the internal carotid artery was legated. After the operation the wound was treated with penicillin potassium salt, the skin was sutured, and treated with $2 \%$ solution of iodine.

All animals were divided into groups with 20 rats in each: group 1 - intact animals without any interventions; group 2 - "false-operated" animals with surgical intervention but without cerebral artery occlusion and any treatment.

Animals with experimental chronic ischemia received different pharmacotherapeutical variants and therefore were divided into four groups:

group 3 - a control group with intranasal or intraperitoneal introduction of $0.9 \% \mathrm{NaCl}$ solution;

group 4 - received the basic therapy alone (piracetam $-200 \mathrm{mg} / \mathrm{kg} /$ day and vinpocetine $-0.7 \mathrm{mg} /$ $\mathrm{kg} /$ day for 10 days);

group 5 - in addition to the basic therapy antioxidant was given intraperitoneally at the dosage of $0.16 \mathrm{ml} / \mathrm{kg} /$ day for 10 days;

group $6-$ a stress-limiting preparation, containing delta sleep-inducing peptide at the dosage of $150 \mu \mathrm{g} / \mathrm{kg} /$ day for 10 days, was introduced in combination with the basic therapy.

Pharmacological intervention started 10 days after ischemia simulation, as stabilization of the functional state with formation of the chronic stage of cerebral ischemia occurred in this period. Preparations were given every morning.

Preliminary assessment of resistance to stress was not done, as these tests might influence the dynamics of stress and compensatory-adaptive reaction indices during further treatment. Besides, usage of Wistar line animals in the experiment, which are known to be poorly stress-resistant, allows the comparison of the experimental and clinical material.

Ten days after acute ischemia simulation, parameters of compensatory-adaptive reactions, showing disadaptation and development of chronic cerebral ischemia, were registered. Dynamics of morphofunctional indices was evaluated on day 10,30 , and 60 . Further observations were considered useless as changes might appear in the brain as a result of aging.

The following indices were analyzed: parameters of behavioral activity of the animals, the state of free radical processes, blood stress reactions, morphological changes in the brain tissue in the postoperative period (on day 60), animal survival in the remote postoperative period (on day 60).

Blood for biochemical tests was collected always at the same time on day 10 and 60 .

The level of tissue hypoxia was evaluated by the content of lactate and pyruvate in rats blood. Quantitatively lactate was determined by enzymatic method using lactate dehydrogenase (LDH) in glycine/hydrozene buffer. The intensity of free radical processes in the rats blood plasma was determined by induced chemiluminescence technique using chemiluminometer BHL-06 (Russia). A leukogram with calculation of leukocyte ratio and electrophoretic mobility of erythrocytes were investigated (by HaramonenkoRakityanskaya technique). Morphologic study of the 
perifocal area in the fifth layer of the cerebral cortex, containing pyramidal neurons, was carried out 2 months following ischemia simulation. Brain tissue samples were fixed in $10 \%$ solution of neutral buffered formalin, dehydrated in alcohols of increasing concentration and imbedded in paraffin. Sections $7 \mu \mathrm{m}$ thick were prepared on microtome Leica SM 2000R (Leica, Germany) and stained by hematoxylin and eosin, Nissl stain. Neurons and neuroglia cells in the examined field of view were countedusing light microscope DMLS (Leica, Germany) and visualization software. The quantity of cells was determined on 15 brain sections of each animal.

Statistical processing of the data was performed with the help of applied software package Statistica 6.0 (StatSoft, Inc., USA). Differences obtained by comparative analysis were considered statistically significant at $p<0.05$.

Results and Discussion. Experimental chronic cerebral ischemia is known to result in considerably marked behavioral disorders, which are preserved in the rats during the entire period of observation. Anxiety growth, prolongation of freezing reaction, decreaseof motion activity and learning ability (Table 1), characterizing stress reaction and reduction of compensatory-adaptive capabilities in animals, were revealed. Absence of movement disorder (paresis, stroke) indicates to the restoration of neurological functions in the period of chronic ischemia. Partial compensation of functions is connected with a specific blood supply in rats, e.g. a more developed collateral blood supply system.
Examination of the laboratory indices showed increase of electrophoretic erythrocyte mobility and leukocyte ratio, as well as reduction of lymphocyte content (Table 2) and activation of lipid peroxidation processes.

Changes of neuroglia and neurons ratio in the fifth layer of the brain cortex were observed in the period of experimental chronic cerebral ischemia (Table 3). The value of neuroglia/neurons ratio in the animals with cerebral ischemia was $77 \%$ higher compared to the intact animals. Total quantity of neurons of the motor cortex decreased, the ratio of nuclear and nuclear-free neurons reduced.

Survival in the group of the experimental animals with chronic cerebral ischemia following 60 days was lower than in the groups of the intact and "false-operated" animals, demonstrating insufficiency of compensatory processes.

Thus, in simulated chronic cerebral ischemia the stringency of compensatory-adaptive processes preserved, as seen by the changes of behavioral and laboratory indices. It is suggested that in such a longacting stress-factor as local ischemia the balance in the pro- and antistress system is broken, diminishing compensatory capabilities in the experimental animals.

The analysis of the effect of neuroprotective and antistress therapy on the brain condition and compensatory capabilities of the experimental animals in simulated cerebral ischemia showed, that application of any of the suggested treating complexes (groups 4-6) increases animal survival rate relative to the

Ta ble 1

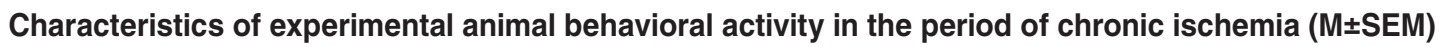

\begin{tabular}{lccccc}
\hline \multicolumn{1}{c}{ Animal groups } & AL & FR & VMA & HMA & CPAR \\
Intact & $6.7 \pm 1.8$ & $28.8 \pm 8.2$ & $11.5 \pm 1.9$ & $106.8 \pm 15.7$ & $23.0 \pm 2.8 / 120.0 \pm 1.8$ \\
\hline "False-operated" & $7.4 \pm 1.2$ & $56.8 \pm 9.8$ & $10.8 \pm 1.7$ & $96.8 \pm 18.5$ & $21.5 \pm 3.1 / 124.0 \pm 1.9$ \\
\hline Chronic cerebral ischemia & $11.3 \pm 0.5^{*+}$ & $154.0 \pm 43.2^{*+}$ & $2.6 \pm 3.1^{*+}$ & $55.3 \pm 21.9^{*+}$ & $63.0 \pm 20.5 / 109.4 \pm 12.1^{*+}$ \\
\hline
\end{tabular}

$\mathrm{N}$ o t e. AL: anxiety level (standard units); FR: duration of freezing reaction (s); VMA: vertical motion activity (quantity of "rising-ups"); HMA: horizontal motion activity (quantity of crossed squares); CPAR: conditioned passive avoidance reaction (time of learning/time of reproduction). * Statistically significant difference of values with the intact group $(p<0.05) ;{ }^{+}$with the "false-operated" animals $(p<0.05)$.

Table 2

Indices of stress and compensatory reactions in experimental chronic cerebral ischemia (M $\pm S E M)$

\begin{tabular}{|c|c|c|c|c|c|c|c|}
\hline Animal groups & $\begin{array}{c}\text { EPME } \\
\left(\mu \mathrm{m} \cdot \mathrm{cm} \mathrm{V}^{-1} \mathrm{~s}^{-1}\right)\end{array}$ & LR & $\begin{array}{l}\text { Lactate/ } \\
\text { pyruvate }\end{array}$ & $\operatorname{Imax}(\mathrm{mV})$ & $\begin{array}{l}\text { S (standard } \\
\text { units) }\end{array}$ & $\begin{array}{c}\text { Nuclear/ } \\
\text { nuclear-free } \\
\text { neurons }\end{array}$ & Survival (\%) \\
\hline Intact & $1.31 \pm 0.02$ & $7.10 \pm 0.07$ & $3.2 \pm 1.0$ & $3.1 \pm 0.2$ & $32.9 \pm 1.5$ & $4.6 \pm 0.3$ & 100 \\
\hline "False-operated" & $1.32 \pm 0.02$ & $6.90 \pm 0.07$ & $3.3 \pm 1.0$ & $3.2 \pm 0.2$ & $33.6 \pm 1.5$ & $4.7 \pm 0.2$ & 100 \\
\hline Chronic cerebral ischemia & $1.46 \pm 0.07^{\star+}$ & $9.30 \pm 0.05^{\star+}$ & $16.8 \pm 2.6^{\star+}$ & $4.1 \pm 0.4^{\star+}$ & $61.4 \pm 0.6^{\star+}$ & $1.6 \pm 0.2^{\star+}$ & $44^{*+}$ \\
\hline
\end{tabular}

N o t e. EPME: electrophoretic mobility of erythrocytes; LR: leukocyte ratio; Imax: intensity of free radical oxidation processes; $\mathrm{S}$ : light sum. * Statistically significant difference of values with the intact group $(p<0.05)$; + with the "false-operated" animals $(p<0.05)$. 
Table 3

The number of neuroglia cells and neurons in the perifocal area of the rats' fifth cortex layer (day 60 of cerebral ischemia)

\begin{tabular}{|c|c|c|c|}
\hline Animal groups & Neurons & Neuroglia cells & Neuroglia cells/neurons \\
\hline Intact $(\mathrm{n}=20)$ & $56.15 \pm 1.35^{\star \#}$ & $51.24 \pm 1.60^{\star \#}$ & $0.91 \pm 0.02^{* \#}$ \\
\hline "False-operated" (n=20) & $57.12 \pm 2.17^{\star \#}$ & $52.31 \pm 1.70^{\star \#}$ & $0.91 \pm 0.03^{\star \#}$ \\
\hline Control group $(n=20)$ & $41.26 \pm 2.23^{\# v}$ & $68.40 \pm 2.27^{\# v}$ & $1.66 \pm 0.06^{\# v}$ \\
\hline Basic therapy $(n=20)$ & $48.18 \pm 2.34^{v}$ & $62.52 \pm 2.21^{\star v}$ & $1.29 \pm 0.02^{* v}$ \\
\hline Basic and antioxidant therapy $(n=20)$ & $46.84 \pm 2.44^{v}$ & $63.50 \pm 2.17^{\star v}$ & $1.35 \pm 0.07^{\star v}$ \\
\hline Basic and stress-limiting therapy $(n=20)$ & $55.33 \pm 2.18^{\star \#}$ & $56.82 \pm 2.61^{*}$ & $1.020 \pm 0.023^{\star \#}$ \\
\hline
\end{tabular}

$\mathrm{N}$ o t e. Data are presented as $M \pm S D$, where $M$ is mean value, $S D$ is standard deviation. * Statistically significant difference of values with the control group $(p<0.05) ;{ }^{~}$ with the group receiving only basic therapy $(p<0.05) ;{ }^{v}$ with the intact animals $(p<0.05)$.

\begin{tabular}{|c|c|c|c|}
\hline \multicolumn{4}{|c|}{$\begin{array}{l}\text { Dynamics of motion activity indices depending on the application of various } \\
\text { therapeutic complexes }\end{array}$} \\
\hline Animal groups & Day 10 & Day 30 & Day 60 \\
\hline \multicolumn{4}{|c|}{ Vertical motion activity } \\
\hline Intact & $11.5 \pm 1.9(n=20)$ & $10.0 \pm 1.8(n=20)$ & $10.4 \pm 2.2(n=20)$ \\
\hline "False-operated" & $10.80 \pm 1.73(n=20)$ & $7.10 \pm 1.62(n=20)$ & $8.20 \pm 1.39(n=20)$ \\
\hline Control group & $3.08 \pm 0.97(n=18)$ & $1.0 \pm 0.3^{*}(n=10)$ & $1.0 \pm 0.4^{*}(n=8)$ \\
\hline Basic therapy & $2.66 \pm 0.88(n=16)$ & $1.67 \pm 0.67(n=12)$ & $4.67 \pm 1.67^{\#}(n=12)$ \\
\hline Basic and antioxidant therapy & $2.9 \pm 0.9(n=16)$ & $0.7 \pm 0.2^{\star+}(n=12)$ & $0.7 \pm 0.3^{\star+}(n=12)$ \\
\hline Basic and stress-limiting therapy & $2.6 \pm 0.6(n=16)$ & $1.4 \pm 0.7^{\star}(n=16)$ & $5.5 \pm 4.1^{\#}(n=16)$ \\
\hline \multicolumn{4}{|c|}{ Horizontal motion activity } \\
\hline Intact & $106.8 \pm 15.7(n=20)$ & $89.9 \pm 10.9(n=20)$ & $90.2 \pm 11.7(n=20)$ \\
\hline "False-operated" & $96.8 \pm 18.5(n=20)$ & $106.7 \pm 17.9(n=20)$ & $104.9 \pm 18.0(n=20)$ \\
\hline Control group & $46.3 \pm 12.0(n=18)$ & $20.33 \pm 5.70^{*}(n=10)$ & $8.3 \pm 8.4^{*}(n=8)$ \\
\hline Basic therapy & $59.7 \pm 16.4(n=16)$ & $64.8 \pm 7.7^{\#}(\mathrm{n}=12)$ & $70.1 \pm 6.9^{\#}(n=12)$ \\
\hline Basic and antioxidant therapy & $42.5 \pm 9.9(n=16)$ & $20.7 \pm 10.3^{*+}(n=12)$ & $10.0 \pm 5.4^{*+}(n=12)$ \\
\hline Basic and stress-limiting therapy & $50.2 \pm 9.1(n=16)$ & $52.5 \pm 6.2^{\#}(n=16)$ & $55.7 \pm 9.8^{\#}(n=16)$ \\
\hline
\end{tabular}

$\mathrm{N}$ o t e. Data are presented as $M \pm S D$, where $M$ is mean value, SD is standard deviation. The number of survived animals is indicated. * Statistically significant difference of values with the indices of day 10 $(p<0.05) ;{ }^{*}$ with the control group $(p>0.05) ;{ }^{+}$with the group receiving only basic therapy $(p<0.05)$.

control group. The course of basic neuroprotective therapy improved the survival rate of the animals in chronic cerebral ischemia by $31 \%$. A combination of neuroprotective therapy with the antioxidant provided survival of $75 \%$ of animals, reaching $100 \%$ when combined with the stress-limiting preparation.

Three main characteristics of rats behavior: horizontal motion activity (HMA), measured by the quantity of the crossed squares in the "open field"; vertical motion activity (VMA), defined by the number of rising-ups on hind-limbs; and a conditioned passive avoidance reaction (CPAR) - have been analyzed in dynamics (Tables 4 and 5).
In all operated animals the characteristics of VMA and HMA sharply reduced on day 10 of the cerebral ischemia compared to the intact animals. VMA characteristics rose by day 60 relative to the control group, when the basic neuroprotective therapy was used alone. If the antioxidant was included into the therapeutic complex, the characteristics decreased by day 30 and remained low till day 60 , differing from the control group and from the group, receiving the neuroprotective therapy alone.

In the group, receiving the stress-limiting preparation, VMA index reduced by day 30 , though the following observation showed its gradual increase. HMA characteristics in the control group were falling during 
Table 5

Dynamics of conditioned passive avoidance reaction indices depending on the application of various therapeutic complexes

\begin{tabular}{|c|c|c|c|c|c|c|}
\hline \multirow{2}{*}{ Animal groups } & \multicolumn{2}{|c|}{ Day 10} & \multicolumn{2}{|c|}{ Day 30} & \multicolumn{2}{|c|}{ Day 60} \\
\hline & Learning (s) & Reproduction (s) & Learning (s) & Reproduction (s) & Learning (s) & Reproduction (s) \\
\hline Intact & $\begin{array}{c}21.5 \pm 3.1 \\
(n=20)\end{array}$ & $\begin{array}{c}120.0 \pm 1.8 \\
(n=20)\end{array}$ & $\begin{array}{c}18.5 \pm 7.5 \\
(n=20)\end{array}$ & $\begin{array}{c}179.5 \pm 0.5 \\
(n=20)\end{array}$ & $\begin{array}{c}18.7 \pm 9.9 \\
(n=20)\end{array}$ & $\begin{array}{c}172.0 \pm 7.3 \\
(n=20)\end{array}$ \\
\hline "False-operated" & $\begin{array}{c}23.0 \pm 2.8 \\
(n=20)\end{array}$ & $\begin{array}{c}124.0 \pm 1.9 \\
(n=20)\end{array}$ & $\begin{array}{c}25.2 \pm 1.4 \\
(n=20)\end{array}$ & $\begin{array}{c}119.0 \pm 2.2 \\
(n=20)\end{array}$ & $\begin{array}{c}23.1 \pm 1.7 \\
(n=20)\end{array}$ & $\begin{array}{c}122.5 \pm 2.1 \\
(n=20)\end{array}$ \\
\hline Control group & $\begin{array}{c}65.7 \pm 10.6^{\#} \\
(n=18)\end{array}$ & $\begin{array}{c}108.127 .3 \\
(n=18)\end{array}$ & $\begin{array}{c}66.024 .0^{\#} \\
(n=10)\end{array}$ & $\begin{array}{c}101.529 .9^{\#} \\
(n=10)\end{array}$ & $\begin{array}{c}56.05 .1^{\#} \\
(n=8)\end{array}$ & $\begin{array}{c}106.29 .3^{*} \\
(n=8)\end{array}$ \\
\hline Basic therapy & $\begin{array}{l}64.5 \pm 10.5^{\#} \\
(n=16)\end{array}$ & $\begin{array}{c}107.0 \pm 23.0 \\
(n=16)\end{array}$ & $\begin{array}{l}46.5 \pm 0.5^{\star \# v} \\
\quad(n=12)\end{array}$ & $\begin{array}{c}156.0 \pm 1.5^{\star v *} \\
(n=12)\end{array}$ & $\begin{array}{c}39.3 \pm 5.2^{* \text { *v }} \\
(n=12)\end{array}$ & $\begin{array}{c}141.0 \pm 20.8^{* \# v} \\
(n=12)\end{array}$ \\
\hline Basic and antioxidant therapy & $\begin{array}{l}57.8 \pm 19.5^{\#} \\
\quad(n=16)\end{array}$ & $\begin{array}{c}111.0 \pm 12.4 \\
(n=16)\end{array}$ & $\begin{array}{c}44.6 \pm 2.7^{\#} \\
(n=12)\end{array}$ & $\begin{array}{c}146.0 \pm 21.5^{\star \#} \\
(n=12)\end{array}$ & $\begin{array}{c}47.0 \pm 21.0^{*} \\
(n=12)\end{array}$ & $\begin{array}{c}150.0 \pm 12.7^{\star v \#} \\
(n=12)\end{array}$ \\
\hline Basic and stress-limiting therapy & $\begin{array}{c}66.0 \pm 10.0^{*} \\
(n=16)\end{array}$ & $\begin{array}{c}109.6 \pm 18.5 \\
(n=16)\end{array}$ & $\begin{array}{c}31.0 \pm 7.21^{\# \star v+} \\
(n=16)\end{array}$ & $\begin{array}{c}180.0 \pm 0.01^{\star v+} \\
(n=16)\end{array}$ & $\begin{array}{c}32.9 \pm 10.5^{\# v} \\
(n=16)\end{array}$ & $\begin{array}{c}178.0 \pm 0.01^{\star+v} \\
(n=16)\end{array}$ \\
\hline
\end{tabular}

$\mathrm{N}$ o t e. Data are presented as $M \pm S D$, where $M$ is mean value, $S D$ is standard deviation. The number of survived animals is indicated. * Statistically significant difference of values with the indices of day $10(p<0.05)$; ${ }^{*}$ with the intact group $(p<0.05) ;{ }^{v}$ with the control group $(p<0.05) ;{ }^{+}$with the group receiving only basic therapy $(p<0.05)$.

the whole period of observation similar to the group, receiving a combination of the basic and antioxidant therapy. In the groups, receiving the basic therapy alone, and the basic and stress-limiting therapy reduction of HMA was not noted.

Thus, increase of VMA and stabilization of HMA by day 60 in experimental cerebral ischemia occurred, when the basic therapyand its combination with the stresslimiting therapy were used.

The study of conditioned passive avoidance reaction (CPAR) was used to assess learning ability and memory during application of various therapeutic complexes (See Table 5). It was established that, learning ability did not restore in the animals of the control group in the remote period of cerebral ischemia. Improvement of learning ability was noted, when basic therapy alone was conducted, but CPAR characteristics remained lower than in the group of the intact animals. Similar dynamics was revealed in the group, receiving the basic and antioxidant therapy. In the group receiving the basic and stresslimiting therapy learning abilities were noted to restore: by day 30 the time of being in the white compartment (indicator of "reproduction") reached the level of the intact animals and remained till day 60 . The time of learning diminished, though did not reach the level of the intact animals.

To evaluate the state of nonspecific stress system electrophoretic mobility of erythrocytes (EPME) and leukocyte ratio in the rats were studied. In the control group EPME (Table 6) preserved increased levels from day 10 till 60 . $(p<0.05)$.
Similar situation was observed when the antioxidant was included in the therapeutic complex. In the group of animals receiving the basic therapy alone and in the group receiving the basic and stress-limiting therapy statistically significant reduction of EPME occurred by day 60 , indicating to the approach of stress reaction indices to the physiological level. The dynamics was more marked in the group, receiving the stress-limiting therapy.

Dynamics of leukogram in the groups, receiving the antioxidant and stress-limiting therapy, was unidirectional: the lymphocyte level, reduced on day 10 , elevated by day 60 up to the level of the intact animals. In the group without any therapy the lymphocyte level did not reach the normal values by day 60 . Dynamics of the leukocyte

Table 6

Dynamics of electrophoretic mobility of erythrocytes depending on the application of various therapeutic complexes $\left(\mu \mathrm{m} \cdot \mathrm{cm} \mathrm{V}^{-1} \mathrm{~s}^{-1}\right)$

\begin{tabular}{lcc}
\hline \multicolumn{1}{c}{ Animal groups } & Day 10 & Day $\mathbf{6 0}$ \\
\hline Intact & $1.31 \pm 0.02(n=20)$ & $1.32 \pm 0.02(n=20)$ \\
\hline "False-operated" & $1.32 \pm 0.02(n=20)$ & $1.31 \pm 0.03(n=20)$ \\
\hline Control group & $1.46 \pm 0.07(n=18)$ & $1.63 \pm 0.03^{*}(n=8)$ \\
\hline Basic therapy & $1.50 \pm 0.05(n=16)$ & $1.47 \pm 0.03^{* *}(n=12)$ \\
\hline Basic and antioxidant therapy & $1.51 \pm 0.03(n=16)$ & $1.67 \pm 0.02^{*}(n=12)$ \\
\hline Basic and stress-limiting therapy & $1.44 \pm 0.08(n=16)$ & $1.35 \pm 0.03^{* *+}(n=16)$ \\
\hline
\end{tabular}

$\mathrm{N}$ ote. The number of survived animals is indicated. * Statistically significant difference of values with the indices of day $10(p<0.05) ; \#$ with the control group $(\mathrm{p}<0.05) ;{ }^{+}$with the group receiving only basic therapy 
T a ble 7

\begin{tabular}{|c|c|c|c|c|}
\hline \multirow{2}{*}{ Animal groups } & \multicolumn{2}{|c|}{ Lactate/pyruvate } & \multicolumn{2}{|c|}{$\operatorname{Imax} / S$} \\
\hline & On day 10 & On day 10 & On day 10 & On day 10 \\
\hline Intact & $3.70 \pm 1.03$ & $5.84 \pm 0.30$ & $0.101 \pm 0.003$ & $0.095 \pm 0.003$ \\
\hline "False-operated" & $3.20 \pm 1.01$ & $5.85 \pm 0.21$ & $0.094 \pm 0.003$ & $0.096 \pm 0.004$ \\
\hline Control group & $16.60 \pm 2.62^{v}$ & $24.79 \pm 2.62^{\star v}$ & $0.059 \pm 0.002^{v}$ & $0.066 \pm 0.004^{v}$ \\
\hline Basic therapy & $16.90 \pm 1.09 v$ & $20.48 \pm 8.07^{v}$ & $0.062 \pm 0.002^{v}$ & $0.089 \pm 0.003^{* \#}$ \\
\hline Basic and antioxidant therapy & $16.20 \pm 2.03^{v}$ & $30.68 \pm 5.24^{\star v}$ & $0.060 \pm 0.003$ & $0.076 \pm 0.004^{\star *}$ \\
\hline Basic and stress-limiting therapy & $17.0 \pm 1.15$ & $11.41 \pm 2.28^{\star \# v}$ & $0.058 \pm 0.005$ & $0.085 \pm 0.002^{\star \#}$ \\
\hline
\end{tabular}

$\mathrm{N}$ o t e. Data are presented as $\mathrm{M} \pm \mathrm{SD}$, where $\mathrm{M}$ is mean value, $\mathrm{SD}$ is standard deviation. ${ }^{*}$ Statistically significant difference of values with the indices of day $10(p<0.05)$; * with the control group $(p<0.05)$; $\checkmark$ with the intact animals $(p<0.05)$.

ratio different from the control group was noted in all groups receiving therapy. Decrease of the leukocyte ratio speaks of stress reaction reduction in these groups.

Investigation of oxidizing processes involved determination of lactate and pyruvate ratio in the animals' arterial blood and antioxidant activity of blood plasma. The ability of blood substrates to inhibit the oxidative processes was expressed by the ratio Imax/S. Dynamics of oxidative processes indices using various therapeutic complexes is presented in Table 7.

Predominance of anaerobic processes with the reduction of pyruvate utilization in the Krebs cycle in the remote period of cerebral ischemia was observed in all animals compared to the intact ones. In the group, receiving the basic therapy and in that of receiving the basic and stress-limiting therapy increase of lactate/ pyruvate ratio on day 60 was not found compared to day 10. Moreover, in the group, receiving the stresslimiting preparation, decrease of this index was noted by day 60 .

On day 10 antioxidant activity of blood plasma (Imax/ S) was lower in animals with cerebral ischemia relative to the intact rats. By day 60 this index remained low in the control group. On the contrary, increase of antioxidant activity by day 60 was foundin all groups receiving treatment compared to day 10 and the control group.

The results of the motor cortex study in the remote cerebral ischemia are presented in Table 3. Decrease of neuron number and increase of neuroglia cells compared to the intact animals was found in the experimental animals of all groups excluding the rats, receiving the stress-limiting therapy. The most marked increase of neuroglia cells was in the control group. Thus, administration of the antistress therapy activates neurotrophic processes in the nerve tissue and improves neurons and neuroglia cells viability.

Conclusion. Imbalance in the ratio of stressactivating and stress-limiting systems is likely to be preserved during the entire period of observation (60 days) in the experimental animals with simulated chronic cerebral ischemia, which is seen by the changes in the laboratory indices, leading to the deficiency of adaptive and compensatory processes in such animals, and almost two fold reduction of their viability by the end of post-ischemic observation period (60 days).

The course of basic neuroprotective therapy improves the viability of the experimental animals in the remote period of chronic cerebral ischemia by $31 \%$ and causes a neurotrophic effect. A combination of the basic neuroprotective therapy and antistress preparations provides viability of $75 \%$ of animals in case of antioxidant use, and $100 \%$ of animals, when stresslimiting preparations are given. Inclusion of the stresslimiting preparation in the therapeutic complex intensifies a neurotrophic effect.

Study Funding and Conflicts of Interest. This study was not supported by any financial sources and there is no topic specific conflict of interest related to the authors of this study.

\section{References}

1. Kukhtevich V.V. Compensatory-adaptive reactions of the organism in chronic illnesses save it from more severe diseases. Meditsinskaya kafedra 2002; 3: 108-114.

2. Martyushev-Poklad A.V., Voronina T.A. Stress-limiting systems and neuronal plasticity in pathogenesis of psychic and neurologic disorders. Obzory po klinicheskoy farmakologii $i$ lekarstvennoy terapii 2003; 2(4): 15-25.

3. Naryzhnaya N.V. Antiarrhythmic effects of adaptation to hypoxia and stress are realized via various types of opioid receptors. Patogenez 2008; 3: 78.

4. Arkhipenko Yu.V. Adaptation to changing level of $\mathrm{O}_{2}$ increase myocardial membrane resistance to reactive oxygen species. In: International society for adaptive medicine (ISAM): abstracts of VIII World Congress. Moscow; 2006; p. 41.

5. Rattan S.I.S. Anti-aging and life-prolonging hormetic effects of mild stress. In: International society for adaptive medicine (ISAM): abstracts of VIII World Congress. Moscow; 2006; p. 63. 
6. Agadzhanyan N.A. Adaptatsionnaya i etnicheskaya fiziologiya: ekologiya i zdorov'e cheloveka. V kn.: Ekologofiziologicheskie problemy adaptatsii: materialy XIV Mezhdunarodnogo simpoziuma [Adaptive and ethnic physiology: ecology and human health. In: Ecologic and physiologic problems of adaptation: proceedings of XIV International Symposium]. Moscow: Izd-vo RUDN; 2009; p. 3-7.

7. Burton T., Farley D., Rhea A. Stress-induced somatization in spouses of deployed and nondeployed servicemen. J Am Acad Nurse Pract 2009; 21(6): 332-339, http://dx.doi.org/10.1111/ j.1745-7599.2009.00411.x.

8. Carson A.J., Ringbauer B., MacKenzie L. Neurological disease, emotional disorder, and disability: they are related: a study of 300 consecutive new referrals to a neurology outpatient department. J Neurol Neurosurg Psychiatry 2000; 68: 202-206, http://dx.doi.org/10.1136/jnnp.68.2.202.

9. Medin J., Ekberg K., Nordlund A., Eklund J. Organisational change, job strain and increased risk of stroke. A pilot study. Work 2008; 31(4): 443-449.

10. Gipoksiya. Adaptatsiya, patogenez, klinika [Hypoxia. Adaptation, pathogenesis, clinical picture]. Pod red. Shevchenko Yu.L. [Shevchenko Yu.L. (editor)]. Saint Petersburg: Elbi-SPb; 2000; 384 p.

11. Funktsional'no-metabolicheskie osobennosti zhivotnykh $s$ razlichnoy individual'noy rezistentnost'yu k gipoksii. Problemy gipoksii: molekulyarnye, fiziologicheskie i meditsinskie aspekty [Functional and metabolic characteristics of animals with various individual resistance to hypoxia. Problems of hypoxia: molecular, physiological and medical aspects]. Pod red. Luk'yanovoy L.D., Ushakova I.B. [Luk'yanova L.D., Ushakov I.B. (editors)]. Moscow-Voronezh: Izd-vo "Istoki"; 2004; p. 156-159.

12. Maksimova M.Y., Domashenko M.A., Tanashyan M.M. Current approaches to preventing and treating chronic cerebral circulatory disorder. Nevrologiya, neyropsikhiatriya $i$ psikhosomatika 2012; 4: 88-91.

13. Rumyantseva S.A., Silina E.V. Energokorrektsiya $i$ kachestvo zhizni pri khronicheskoy ishemii mozga [Energy correction and quality of life in chronic cerebral ischemia]. Moscow: Meditsinskaya kniga; 2007.

14. Suslina Z.A., Fedin A.I., Rumyantseva S.A., et al. Clinical efficacy of cytoflavin in discirculatory encephalopathy - chronic cerebral ischemia (results of multicenter randomized study). Vestnik Sankt-Peterburgskoy gosudarstvennoy meditsinskoy akademii im. I.I. Mechnikova 2005; 3(6): 7-14.

15. Gannushkina I.V., Konorova I.L., Koplik E.V., Antelava A.L. Correction of cerebral ischemia in low-resistant animals with an antistress drug Deltaran. Bulletin of Experimental Biology and Medicine 2006; 141(3): 288-291, http://dx.doi. org/10.1007/s10517-006-0152-x.

16. Konorova I.L., Gannushkina I.V., Koplik E.V., Antelava A.L. Deltaran prevents an adverse effect of emotional stress on the course of cerebral ischemia in low-resistant animals. Bulletin of Experimental Biology and Medicine 2006; 141(5): 564-566, http://dx.doi.org/10.1007/s10517-0060221-1.

17. Sudakov K.V. Results and prospects of the development of the theory of functional systems. Vestnik Rossiyskoy Akademii Meditsinskikh Nauk 2009; 8: 3-11.

18. Sudakov K.V., Umriukhin P.E., Rayevsky K.S. Delta-sleep inducing peptide and neuronal activity after glutamate microiontophoresis: the role of NMDA-receptors. Pathophysiology 2004; 11(2): 81-86, http://dx.doi.org/10.1016/ j.pathophys.2004.03.003.

19. Gusev E.I., Nikiforov A.S., Gekht A.B. Lekarstvennye sredstva v nevrologicheskoy klinike [Medicaments in neurological clinics]. Moscow: MEDpress-inform; 2003. 